\title{
Cam Deformity and Epiphyseolysis Capitis Femoris
}

\author{
Michael Memminger* \\ Department of Orthopedics and Traumatology, Hospital Montebelluna, Italy
}

Submission: June 27, 2018; Published: July 12, 2018

*Corresponding author: Michael Memminger, Department of Orthopedics and Traumatology, Hospital Montebelluna, Via Togliatti, 1 I-31044 Montebelluna, Italy, Tel: 0039 3493463097; Email: memminger@hotmail.com

\begin{abstract}
Is the cam deformity of the proximal femur the consequence of ephiphyseolysis capitis femoris? Is the same pathological mechanism at the origin of both? We report the clinical case of a young boy, with a slipped femoral epiphysis on the left side and who developed a Cam deformity on the contralateral right healthy hip which has undergone prophylactic screw fixation.

Keywords: Epiphyseolysis capitis femoris; CAM; Impingement
\end{abstract}

\section{Introduction}

What is the reason and origin of the cam deformity of the proximal femur? Which relationship exists between epiphyseolysis capitis femoris and the cam deformity? During slipping of the juvenile femoral epiphysis in the posteromedial direction, the anterior offset gets reduced and an anterior conflict between femoral neck and azetabulum will occur, the anterior hip impingement. If this mechanical conflict persists, the articular cartilage will be damaged early [1]. Only slight slipping can be treated by in situ screw fixation without reduction of the femoral epiphysis; but this usually leads to a CAM deformity [2].

Therefore, in slight slipping Leunig et al. [3] suggest in situ fixation and simultaneous arthroscopic femoral head-neck trimming to prevent early damage to the articular cartilage by impingement. Moderate and strongly slipped femoral epiphyses are treated by surgical hip dislocation, subcapital callus resection and reposition of the femoral epiphysis $[3,4]$. Since the contralateral side often slips successively, a prophylactic fixation of the opposite side is advised [5,6]. Is the Cam deformity always the consequence of slipped femoral epiphysis or maybe it is a pathology of the growing plate itself? We present a case of epiphyseolysis capitis femoris, where cam deformity developed on the prophylactically fixed opposite side.

\section{Case Presentation}

16-year slim boy with pain and limping gait. No history of trauma. Clinical examination revealed a Drehmann sign on the left hip. The opposite right hip has full and normal function. No illnesses were known. X-ray investigation of the pelvis and axial view showed a slipped femoral epiphysis backwards of $20^{\circ}$ on the left hip (Figure 1). We discussed the various surgical options which the parents. The boy was treated through in sitú fixation of the left slipped epiphysis with 2 large titanium screws. A prophylactic fixation on the right hip was done by one screw (Figures 2 \& 3). No complications were seen postoperatively. The removal of the screws was proposed at the closure of the growth plates. 2 years after surgery the boy developed a cam deformity and impingement, both on the left and on the right hip: he complained pain with forced flexion and internal rotation of the hips. The x-ray shows a cam deformity on the right and left hip (Figure 4). We corrected first the cam deformity on the rigth site, successively on the left site. Removal of screws wasn't done simultaneously with the neck trimming because the titanium screws had to be removed by over drilling. The postoperative rehabilitation was without problems. The boy reached complete function of the right and left hip without impingement symptoms. 


\section{Orthopedics and Rheumatology Open Access Journal (OROAJ)}

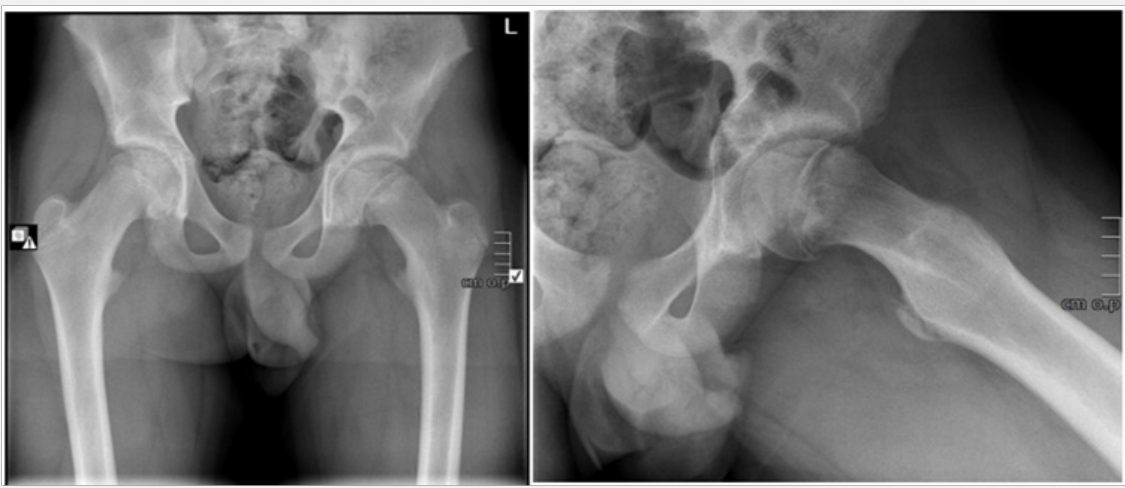

Figure 1: Epiphyseolysis capitis femoris left hip, 14 years old boy.
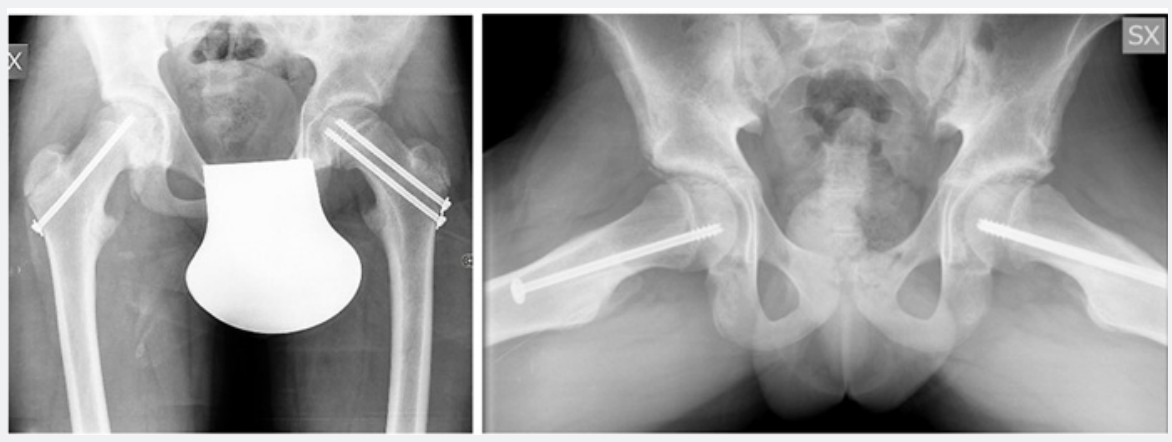

Figure 2: Fixation with 2 titanium screws on left hip. Rigth hip prophylactic fixation with 1 screw. (x-ray after 4 months).

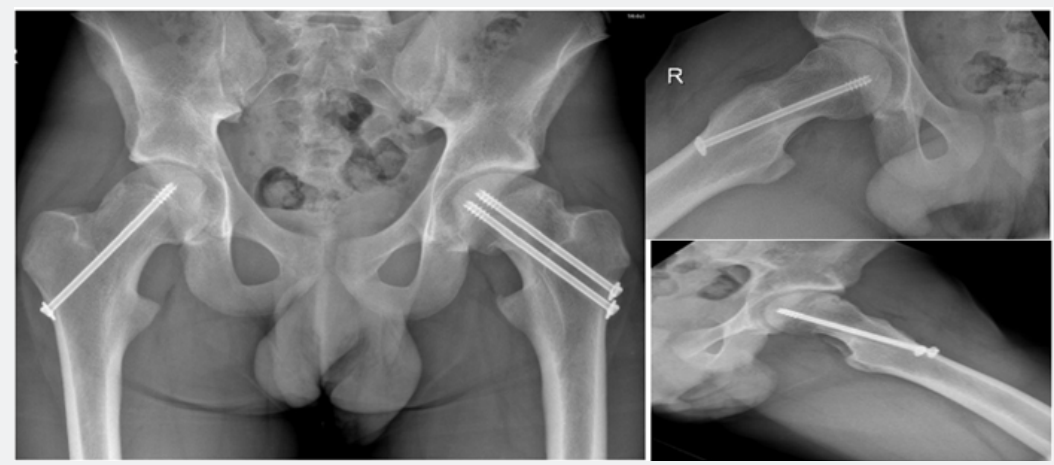

Figure 3: CAM deformity at rigth and Left hip.



Figure 4: After cam resection at rigth hip and left hip (arthroscopically). 


\section{Discussion}

Each Epiphyseolysis capitis femoris, which is fixed in sitú, leads to a reduced offset at the anterior head-neck-junction and can produce impingement. The operation according FishDunn through the surgical hip dislocation (R. Ganz) is therefore suggested also in moderate slipping [7,8]. Slight slipping can be treated by in sitù fixation, but arthroscopical femoral headneck trimming should be considered if the anterior offset at the head-neck junction is reduced [2,4]. Remarkable in this case was the fact, that also on the opposite side, on which no slipping occurred and which was treated prophylactically with 1 screw fixation; also, this hip developed a marked cam deformity with hip impingement and required surgical treatment. Should we presume that an altered femoral growing plate is at the origin of a cam deformity, independently if the femoral epiphysis has slipped or not? Even with a not slipped epiphysis, a cam deformity could develop at the growing plate.

\section{References}

1. Leunig M, Fraitzl CR, Ganz R (2002) Frühe Schädigung des azetabulären Knorpels bei der Epiphyseolysis capitis femoris. Therapeutische Konsequenzen, Der Orthopäde 31(9): 894-899.
2. Klit J, Gosvig K, Magnussen E, Gelineck J, Kallemose T, et al. (2014) Cam deformity and hip degeneration are common after fixation of a slipped capital femoral epiphysis. Acta Orthopaedica 85(6): 585-591.

3. Leunig M, Casillas MM, Hamlet M, Hersche O, Notzli H, et al. (2000) Slipped capital femoral epiphysis: early mechanical damage to the acetabular cartilage by a prominent femoral metaphysis. Acta Orthop Scand 71(4): 370-375.

4. Leunig M, Horowitz K, Manner H, Ganz R (2010) In situ pinning with arthroscopic osteoplasty for mild SCFE: a preliminary technical report. Clin Orthop Relat Res 468(12): 3160-3167.

5. HägglundG (1996) The contralateral hip in slipped capital femoral epiphysis. J Pediatr Orthop 5(3): 158-161.

6. Clement ND, Vats A, Duckworth AD, Gaston MS, Murray AW (2015) Slipped capital femoral epiphysis. Is it worth the risk and cost not to offer prophylactic fixation of the contralateral hip? J Bone Joint 97B(10): 1428-1434.

7. DunnDM (1964) The treatment of adolescent slipping of the upper femoral epiphysis. J Bone Joint Surg Br 46: 621-629.

8. Ganz R, Gill TJ, Gautier E, Ganz K, Krügel N, et al. (2001) Surgical dislocation of the adult hip a technique with full access to the femoral head and acetabulum without the risk of avascular necrosis. J Bone Joint Surg Br 83(8): 1119-1124.

\section{Your next submission with Juniper Publishers will reach you the below assets}

- Quality Editorial service

- Swift Peer Review

- Reprints availability

- E-prints Service

- Manuscript Podcast for convenient understanding

- Global attainment for your research

- Manuscript accessibility in different formats ( Pdf, E-pub, Full Text, Audio)

- Unceasing customer service

Track the below URL for one-step submission https://juniperpublishers.com/online-submission.php 